Revista Kinesis, Santa Maria v.36, n.3, p. 128-140, set-dez. 2018

Centro de Educação Física e Desportos - UFSM

DOI: $105902 / 2316546427533$

Data de submissão: 05-06-2017

Data de Aceite: 18-11-2018

\title{
EDUCAÇÃO FÍSICA E HISTÓRIA: ENTRE CIÊNCIAS E CRISES
}

\author{
PHYSICAL EDUCATION AND HISTORY: BETWEEN SCIENCE AND CRISIS
}

EDUCACIÓN FÍSICA E HISTORIA: ENTRE CIENCIAS Y CRISIS

\author{
Renan Santos Furtado \\ renan.furtado@yahoo.com.br \\ Universidade Federal do Pará - UFPA \\ Carlos Nazareno Ferreira Borges \\ enosalesiano@hotmail.com \\ Universidade Federal do Pará - UFPA
}

\begin{abstract}
RESUMO
Trata-se de um ensaio de reflexão teórica sobre a relação histórica entre a educação física e a ciencia, tanto na Europa como no Brasil. Temos como objetivo central, expor a partir de qual concepção de ciencia, as práticascorporaisse difundiramnamodernidade. Nossoestudo caracteriza-seporserumareflexãoapartir de uma literatura já elaborada, ou seja, um estudo bibliográfico. Como resultado principal, apontamos a granderelaçãoentreopositivismoea educaçãofísicaaolongo dahistória, econcluímosqueessaimbricação, ajudou no atraso histórico nos campos da formação profissional e produção do conhecimento na área.
\end{abstract}

Palavras-Chave: Educação Física; Ciência; Práticas corporais

\begin{abstract}
It is a theoretical reflection on the historical relationship between physical education and science, both in Europe and in Brazil. We have as our central objective, to expose from what conception of science, corporal practices spread in modernity. Our study is characterized by being a reflection from an already elaborated literature, that is, a bibliographical study. As a main result, we point out the great relationship between positivism and physical education throughout history, and we conclude that this imbrication has helped in the historical backwardness in the fields of professional formation and knowledge production in the area.
\end{abstract}

Keywords: Physical Education; Science; Corporal practices

\section{RESUMEN}

Se trata de un ensayo de reflexión teórica sobre la relación histórica entre la educación física y la ciencia, tanto en Europa como en Brasil. Tenemos como objetivo central, exponer a partir de cual concepción de ciencia, las prácticas corporales se han difundido en la modernidad. Nuestro estudio se caracteriza por ser una reflexión a partir de una literatura ya elaborada, es decir, un estudio bibliográfico. Como resultado principal, señalamos la gran relación entre el positivismo y la educación física a lo largo de la historia, y concluimos que esa imbricación, ayudó en el atraso histórico en los campos de la formación profesional y producción del conocimiento en el área.

Palabras Clave: Educación Física; Ciencia; Prácticas corporales 


\section{Introdução}

Neste ensaio, procuraremos discutir a relação histórica da educação física com aspectos da ciência e cientificidade, buscando compreender o teor das práticas científicas elaboradas tanto para intervenção com as práticas corporais, como na pesquisa e produção do conhecimento na educação física.

Nosso estudo caracteriza-se por ser uma revisão e reflexão a partir de uma literatura já elaborada, ou seja, um estudo bibliográfico (SEVERINO 2002). Selecionamos textos que tratam da construção histórica da educação física, e confrontamo-los com referenciais da teoria social que dialogam sobre as concepções de ciência fundadas na modernidade, mais especificamente sobre o positivismo.

Estruturalmente dividiremos este ensaio em dois momentos. Sendo o primeiro de contextualização histórica da educação física na modernidade, e a sua forma científica no período de sua fundação. Em seguida, discutiremos um pouco a respeito da configuração da educação física na sociedade brasileira e a sua relação com a ciência e instituições formativas.

\section{Desenvolvimento}

\subsection{Os capítulos primários da relação entre Educação Física e ciência na modernidade}

Buscaremos brevemente destacar a partir de um recorte da modernidade ${ }^{1} 1$, mais especificamente entre os séculos XIX e XX, apontamentos iniciais das tipologias de práticas científicas da educação física. Fazendo uso das abstrações de Konder (2009a), precisamos fazer uma análise dialética do próprio sentido histórico da ciência e seu papel para o desenvolvimento da humanidade, na superação das barreiras do conhecer, pois, negar essa potencialidade seria um tanto quanto retrogrado politicamente e socialmente reacionário.

Porém, também não podemos ter uma postura ingênua em relação ao desenvolvimento das ciências, sendo assim, ergue-se a tarefa de reflexão crítica sobre a produção do saber, para assim, não cultuarmos ela sem nenhuma forma de criticidade e aceitarmos diversas formas de ideologias e imposições de qualquer face.

\footnotetext{
1 Berman (1986) define a modernidade como a etapa histórica que tem seus germes no começo do século XVI, apogeu no século XIX, e continuidade em nosso tempo. Para o escritor trata-se de um período de intensas mudanças e metamorfoses no espírito e na sociabilidade humana, um verdadeiro turbilhão constante de possibilidades e contradições que colocam a prova todo o conjunto de certezas que a sociedade feudal construiu. Certamente é uma etapa de revoluções, de novas tradições, da industrialização da produção, do avanço das tecnologias, das grandes descobertas das ciências físicas, enfim, do constante risco ou possibilidade da criação da barbárie ou liberdade efetiva, justamente porque, como diria Marx "Tudo o que era sólido se desmancha no ar" (2010, p.43).
} 
O sentido de buscar uso da história nesse momento, não se confunde com o objetivo de contar detalhadamente cada fato ou processo que constituíram a EF brasileira. Trata-se de um esforço certamente arriscado de recorrer à história para encontrar nela os determinantes significativos para o debate da ciência e campos científicos na área da educação física, e isso não quer dizer; negação de uma série de condicionantes sociais que agiram e persuadiram esse "conto" e sim, incorporação dialética e reconhecimento deles como totalidades mais abrangentes e processos mediadores do objeto a ser saturado no plano das abstrações do concreto.

Como sabemos, a década de 80 representou certa etapa de transição, ou crítica no campo acadêmico e educacional da educação física. No entanto, o que se questionou nesse período, Somente pode ser compreendido a partir da releitura de processos históricos determinados, sendo esse, justamente o objeto de nossa reflexão, porém, pensando especificamente a relação entre o desenvolvimento histórico das práticas corporais até a década de 80 e o padrão de ciência utilizado para tal.

Daolio (1997) afirma que muitos processos anteriores ajudaram no dito período de contestação que a década de 80 aspirou em professores e acadêmicos da área. Em especial, passaremos mais fortemente por alguns deles buscando compreender a forma de irradiação de um tipo de pensamento que controlava a educação física nos trâmites políticos, educacionais e da própria produção do conhecimento.

Mas então, em que "linhas ou contextos" estão às raízes desse tipo de prática? O que caracteriza essas expressões corporais como utilitárias e acríticas? Quais motivos fizeram a comunidade da educação física pensar que deveríamos refletir sobre nosso modelo de atuação profissional e até mesmo formação de professores para uma efetiva transformação da educação física brasileira? Como se deram as primeiras aproximações entre educação física e ciência na modernidade?

Soares (2007) apresenta os determinantes sociais do surgimento da educação física na modernidade, sua ligação com um projeto de consolidação de poder da classe burguesa européia principalmente do século XIX. Para essa perpetuação não bastava o controle das forças produtivas e propriedades dos meios de produção, ou seja, do produto e processo do trabalho da fábrica capitalista. Era necessário imputar valores, disseminar certas ideologias e controlar instituições diversas que surgem nesse momento.

A dinâmica do capitalismo exigiu a produção de um novo tipo de homem, adequado aquele novo padrão social, capaz de reproduzir e proliferar uma lógica política e moral; à educação física, resta uma função: cuidar do corpo, enquanto instrumento do trabalho e amortizar qualquer possibilidade de intelecto crítico, reforçando dessa forma o não entendimento por parte de uma grande massa social do processo de dominação presente nesse período. Sobre essa relação entre mundo do capital e práticas corporais, apresentamos a passagem abaixo: 
É nesta perspectiva que podemos entender a Educação Física como a disciplina necessária a ser viabilizada em todas as instâncias, de todas as formas, em todos os espaços onde poderia ser efetivada a construção deste homem novo: no campo, na fábrica, na família, na escola. A educação Física será a própria expressão física do capital. Ela encarna e expressa os gestos automatizados, disciplinados, e se faz protagonista de um corpo "saudável", torna-se receita e remédio para curar os homens de sua letargia, indolência, preguiça, imoralidade, e, desse modo, passa a integrar o discurso médico, pedagógico... familiar (SOARES, 2007, p. 6).

Ainda segundo Soares (2007), sendo o corpo dos indivíduos, mais um instrumento da produção, passava a constituir uma preocupação da classe dominante. Tornava-se primordial nele investir, no entanto, tal investimento deveria ser no sentido adestrar e dominar condutas. Era preciso docilizar o corpo, e desenvolver-lhe a vigor desde cedo, para assim, prepará-lo a sua função da produção e reprodução no mundo do capital.

Marx e Engels (2010) expressam quanto o poder da burguesia tende a se tornar global. Talvez a ideia de mundo globalizado, sem fronteiras, e com a lógica da perversidade fabulizada e mascarada como nos fala Milton Santos (2001), esteja contida nos escritos de Marx e Engels: “Impelida pela necessidade de mercados sempre novos, a burguesia invade todo o globo terrestre. Necessita estabelecer-se em toda parte, explorar em toda parte, criar vínculos em toda parte" (MARX; ENGLES, 2010, p. 43).

Se pensarmos que o escrito acima vem no ápice do século XIX (1848), da constituição ferrenha da luta de classes entre burgueses e proletários. Observamos a percepção dos teóricos que o confronto de classes tende a ser primeiramente uma questão mundial e em segundo plano, uma forma de compreensão muito além de análise do modo de exploração de forças produtivas de uma determinada sociedade exercida via controle do trabalho e da produção de bens materiais por um determinado grupo social.

A categoria da luta de classes aparece como um conjunto amplo de relações que vão se proliferando dentro da sociedade civil. O surgimento do estado burguês mostra a irradiação da noção de luta de classes, assim, às instituições que compõem ou não o dito e a família, por exemplo, passam a expressar esse sentido amplo de relações sociais apresentados por Marx e Engels (2010).

Fica evidente que a noção de luta de classes é um conceito chave, não apenas para entendermos o nosso tempo, mas: "A história de todas as sociedades até hoje existentes é a história da luta de classes" (MARX; ENGELS, 2010, p.42). Luta de classes para esses teóricos não pode ser vista vulgarmente como duelo momentâneo entre duas classes pela direção da sociedade civil e Estado político, ou como costumeiramente ouvirmos falar, luta entre opressores e oprimidos. A luta de classes é antes de tudo uma forma contraditória e antagônica de relação social que vem garantindo a proliferação e desenvolvimento de muitas sociedades. 
É importante ressaltar o caráter contraditório de toda a história da humanidade até hoje conhecida. A contradição é um elemento do próprio movimento histórico, muito maior, por exemplo, que o antagonismo, ou seja, a desigualdade natural entre classes sociais gerada no sistema de valorização do mundo das coisas entre as classes sociais coexistentes. De certo, o antagonismo de classes é uma contradição que precisamos eliminar das relações cotidianas. Contudo, projetar o término das contradições é correr em sentido contrário ao próprio movimento histórico e potencial criativo de homens e mulheres diversos e plurais (KONDER, 2009b).

E a educação física como se tratou brevemente acima, tem seus primeiros passos sistematizados metodologicamente nessa constituição social, passa a ser difundida como parte do ordenamento burguês a todo o globo, adquirindo formas diferentes, porém utilidades bem similares. Os métodos ginásticos, ou escolas européias de ginástica aparecem como a primeira forma sistematizada desse novo tipo de prática corporal, expressando uma espécie de ethos, ou seja, forma de ser do indivíduo e da sociabilidade burguesa por via de atividades corporais e exercícios físicos diversos. Assim, tais métodos expressam a própria forma científica da educação física na modernidade, ou melhor, o sentido regulatório e metódico dessa nova "tradição".

Soares (2005) elucida como se deu a relação entre ciência e ginástica a partir de um estudo do desenvolvimento do método Francês de ginástica, que inicialmente foi construído por Francisco Amoros, o qual curiosamente começou sua sistematização junto à aristocracia espanhola, mas deu coro a seus novos parâmetros de ciência e racionalismo positivista na França com os burgueses aristocratas da época. Isso se deu na década de 20 do século XIX mais especificamente, sua percepção e concepção de ginástica contida em suas obras e em sua intervenção no conjunto da esfera social da época denotavam todo o sentido dessa nova sociedade. Segue abaixo uma expressão sintética dessa forma de pensamento.

[...] a ciência fundamentada de nossos movimentos, de suas relações com nossos sentidos, nossa inteligência, nossos sentimentos, nossos costumes, e o desenvolvimento de todas as faculdades. A ginástica abarca a prática de todos os exercícios que tendem a tornar o homem mais corajoso, mais intrépido, mais inteligente, mais sensível, mais forte, mais astuto, mais desembaraçado, mais veloz, mais flexível e mais ágil e que nos dispõem a resistir a todas as intermpéries das estações, a todas as variações climáticas; a suportar todas as privações e contrariedades da vida; a vencer todas as dificuldades; a triunfar sobre todos os perigos e todos os obstáculos; a prestar, enfim, serviços de destaque ao Estado eà humanidade. A beneficência e a utilidade pública são o objetivo principal da ginástica; a prática de todas as virtudes sociais, de todos os sacrifícios, os mais difíceis e os mais generosos são seus meios; e a saúde, o prolongamento da vida, o aprimoramento da espécie humana, o aumento da força e riqueza individual e pública são seus resultados positivos (AMOROS, apud SOARES, 2005, p. 37-38). 
Antes de comentar a citação, pedimos desculpas aos leitores por fazermos uso de uma tão extensa. Porém, acreditamos que da referida podemos extrair interessantes sínteses sobre o ideário de prática corporal a qual a ginástica vinha a representar naquele momento determinado.

Primeiro sua identificação junto a noções da própria ciência, e como fica evidente, da ciência positivista; ditavam as regras do jogo científico e das formas de analisar e intervir na nova sociedade. Se nas fábricas a ideia era da produtividade, do racionalizar para melhor explorar sujeitos castigados de miséria física e espiritual e principalmente do ponto de vista da acumulação do próprio sentido do gênero humano como aponta Marx (2010), em outras instâncias esse ideário também se alastrava. Amoros não ameniza palavras para dizer o caráter utilitário da moralidade burguesa que a ginástica deveria assumir, além de seu papel de submissão ao Estado e a vida pública controlada pela Aristocracia e seguidamente pelos burgueses.

Um pequeno excurso na discussão das bases da filosofia positivista mostra a ampla convergência dessa forma de ciência e o discurso de Amoros. Andery et al, (2014) apresentam algumas características marcantes dessa concepção de mundo a partir de um diálogo direto com a obra de seu percussor, o Francês Augusto Comte (1798-1857). Para o pensador, trata-se de criar uma doutrina capaz de proliferar a ciência dos fenômenos naturais e sociais, tratando de elucidar manifestações imediatas e explicar elas a partir de leis únicas, imutáveis e gerais para toda a humanidade.

Vida humana que para Comte, desenvolve-se em três estados ${ }^{2}$ ou fases (teleologia, metafísica e positiva). Logo, a história tem suas leis para seu desenvolvimento harmônico e individual, assim, servem os sujeitos apenas como perpetuadores da espécie, não podendo atrapalhar a ordem social estabelecida pelas instituições políticas. As mudanças devem ser graduais e ordenadas, sendo a radicalidade de uma revolução estrutural erradicada do imaginário social. Acaba sendo melhor primeiramente mudar os indivíduos antes das estruturas sociais, educar moralmente para a vivência de costumes sadios e da chamada religião da humanidade.

Por fim, o conhecimento científico para Comte passa a ser baseado na observação direta dos fatos que são estabelecidos pelo raciocínio humano, excluindo tentativas de descobertas das possíveis origens ou causas primeiras das manifestações sociais ou naturais.

2 (ANDERY... et al, 2014) afirmam que Comte ver o desenvolvimento da história e do pensamento humana a partir da passagem obrigatória por dois estados, até a chagada ao estágio positivo. Nos estágios teológicos e metafísicos da razão humana os agentes sobrenaturais e entidades supremas ainda são preponderantes na forma de pensar da humanidade. Porém, no estágio positivo o reconhecimento da religião universal da humanidade, do progresso da ciência não como explicação absoluta e historicamente provada, mas sim como eficaz e fática na explicação imediata de fenômenos e das leis do mundo objetivo passam a conotar as características de um novo estágio fundando na manipulação objetiva e racional do ser humano sobre os fatos sociais. 
A ginástica, que explicitamente nas palavras de Amoros e nas elaborações seguintes das outras escolas européias, passa a ser toda forma de exercitar e moldar o corpo, e por meio da própria desenvolver características e principalmente conceitos e valores no campo da maneira de pensar de homens e mulheres a serviço e compromisso de progresso social da sociedade, reproduz o formato positivista de desenvolvimento humano. Justificam-se os discursos da moralidade, do nacionalismo, civismo e coragem como fins de práticas que desenvolvem a agilidade, força e resistência. Os novos ordenamentos sociais, a crença na razão cientificista e desenvolvimento do metabolismo social burguês, colocam a tarefa da educação moral do corpo para a EF.

Podemos inferir a partir da análise dessa sistematização da educação física (ginástica), e da sua forma nessa época, que os objetivos e fins da prática não apontam nesse momento para o acúmulo do potencial cultural e formativo humanista das diversas práticas corporais que faziam parte de um programa ginástico, e sim para o desenvolvimento de características sempre fora da própria atividade. É como se a atividade corporal realizada tivesse fim na moralidade e modo de pensar dominante da própria sociedade que a recebia. Deste modo, o positivismo parece ter sido a filosofia perfeita para o uso social das práticas físicas.

Um grande exemplo disso tudo são as primeiras sistematizações de métodos ou escolas de ginástica, como nos mostra Soares (2007) ao tratar da escola alemã, sueca e francesa. Marinho (2010) a partir de elaborações de Alberto Langlade descreve as características das escolas alemã, nórdica e inglesa. O mais curioso é que tanto Soares, como Marinho nos apontam o tipo de prática que se consolidou na Inglaterra como uma forma de ginástica ou escola.

Porém, a partir de estudos principalmente de Bracht(2005)e Stigger(2005)notamos que o fenômeno ali teve peculiaridades singulares. Estamos falando do surgimento do dito esporte moderno ${ }^{3}$, ou simplesmente esporte na linha teórica defendida pelos autores, muito influenciados por Norbert Elias e Eric Dunning (1992) na obra "A busca da excitação".

Queremos chegar ao sentido da sistematização e funcionamento dessas práticas corporais, em um singular período da história da humanidade, para isso trazemos Soares Novamente:

3 Embora inserido no mesmo contexto e com os próprios objetivos dos métodos tradicionais de ginástica difundidos na Europa, o esporte moderno, ou simplesmente o esporte apresenta e ganha contornos próprios no seu desenvolvimento histórico como sinalizam Bracht (2005) e Stigger (2005). Estamos falando de uma atividade humana que ao padronizar e se apropriar da cultura lúdica existente até então principalmente na Inglaterra, funda uma nova forma de prazer e dispêndio de energia em uma atividade corporal específica. Um novo tipo de jogo capaz de em seu ato preservar o lúdico e o competitivo, a tensão e o divertimento, o choro e o riso, enfim, a nova excitação é tão ampla e atrativa que também se tornou capaz de manipular, controlar e segmentar grupos sociais ao longo da história. 


\begin{abstract}
Apresentando algumas particularidades a partir do país de origem, essas escolas, de um modo geral, possuem finalidades semelhantes: regenerar a raça (não nos esqueçamos o grande número de mortos e de doença); promover a saúde (sem alterar as condições de vida); desenvolver a vontade a coragem, a força, a energia de viver (para servir a pátria nas guerras e na indústria) e, finalmente, desenvolver a moral (que nada mais é do que uma intervenção nas tradições e costumes dos povos) (2007, p.52).
\end{abstract}

Bracht (2014) sinaliza que a forma científica ou de teorização da educação física nesse momento foi feita com premissas pedagógicas, tanto médicas, como morais. As práticas corporais se apresentavam como formas de educação para a saúde ou vida cotidiana, logo, a atividade teórica e de sistematização se fundamentava diretamente por via de referências da biologia, se manifestando como uma atividade do plano da ação; sempre pensada por intelectuais de outras áreas.

Lovisolo (1998), afirma que em sua história, a educação física adentra no nível superior a partir de um conceito ou forma de curso profissionalizante, ou seja, vinculada diretamente a um fazer técnico para determinadas funcionalidades econômicas, políticas e sociais; os saberes práticos que, por exemplo, Amoros realizava sem possuir uma determinada formação para tal, passaram a ser aprendidos em cursos de formação superior.

Podemos perceber uma intensa relação entre um conjunto de instituições e interesses econômicos com o tipo de teorização que se firmou na educação física em sua constituição moderna. Bracht (2014) afirma que a própria formação de intelectuais da área, dispostos a intervir criticamente para o avanço dela, teve seus dias retardados, desta forma, ficamos reféns de um intenso colonialismo epistemológico advindo das ditas ciências consolidadas (Fisiologia, anatomia, medicina e etc.). No próximo tópico, buscaremos estreitar ou nos aproximarmos das relações entre educação física, práticas sistematizadas e Brasil.

\title{
2.2 A constituição de um ideário e pensamento que "marca" a Educação Física brasileira
}

Vimos junto a Marx e Engels, que é tendência do modo de produção capitalista a formação de um mercado mundial, capaz de explorar e difundir ideologias e instituições em todos os lugares do mundo. No Brasil a cena da chegada da educação física não ganhou contornos tão diferentes. Junto aos interesses de reprodução social burguesa a educação física é promulgada no conjunto de nossa sociedade como prática moralizadora de uma nova estrutura social.

O símbolo positivista da ordem e progresso encontra em práticas corporais organizadas e sistematizadas na Europa, e primeiramente na forma ginástica, sua dimensão corporal e ideológica. Da mesma maneira que na Europa servia para todos os setores da 
sociedade como "higienização social", no Brasil, sua vinculação adquire status e função similar. O que muda é a particularidade em questão. Não esqueçamos que se tratava de um país que vivia ainda em regime de escravidão no século XIX, além de desenvolvimento industrial reduzido e concentrado na região sudeste.

Comonãoéafinalidade desteestudoaprofundaro debatehistoriográfico daeducação física brasileira, o importante é apenas mapearmos traços gerais dos acontecimentos. Castellani (2011) observa que a educação física entra no Brasil com grande influência das instituições militares e dos pensamentos médico e higienista; inicialmente os métodos alemão e francês representam a tonalidade dessa prática que passa a adentrar as escolas brasileiras como obrigatória nas redes primárias e secundárias a partir da lei constitucional n.1 da constituição dos Estados Unidos do Brasil, de 10 de novembro de 1937.

O Estado Novo (1937-1945) não só consolidou a burguesia incipiente, como também um modelo de práticas físicas aos moldes de ciências como anatomia e fisiologia, capazes de normatizar a noção do homem como máquina a ser adestrada. A burguesia continua seu projeto de poder e dominação na sociedade brasileira ao longo de todo o século XX, e o esporte passa a ser como também tendência internacional o grande agente da educação física a partir das décadas 40 e 50, atingindo seu ápice na década de 60, principalmente após a segunda guerra mundial, sendo extremamente influente no sistema escolar nacional. Um pouco dessa legitimidade esportiva no cenário mundial e nacional pode ser observada com a passagem a seguir:

Após a segunda guerra mundial, que coincide com o fim da ditadura e do estado novo no Brasil, surgem outras tendências disputando a supremacia no interior da instituição escolar. Destaca-se o método natural austríaco desenvolvido por Gaulhofer e Striecher e o método da Educação Física Desportiva Generalizada, divulgado no Brasil por Auguste Listello. Predomina nesse último a influência do esporte que, no período do pós-guerra, apresenta um grande desenvolvimento, afirmando-se paulatinamente em todos os países sob a influência da cultura europeia como elemento predominante da cultura corporal (COLETIVO DE AUTORES, 2012. p. 53).

A educação física, como Bracht (1997) aponta no texto: "A criança que pratica esporte, respeita as regras do jogo... capitalista", quando adota o esporte, adota o modelo de alto rendimento, exacerba o desempenho e valoriza códigos da sociedade burguesa, no fundo:

Se analisarmos as aulas de Educação Física onde o esporte escolar é iniciado e desenvolvido, veremos que a idéia da aprendizagem do esporte enquanto aprendizagem das técnicas esportivas predomina. Isto porque, para a competição, na verdade, é isto que conta. Permeia, portanto, a busca do rendimento atlético-esportivo, que é condição para as possibilidades de vitória nas competições (BRACHT, 1997, p. 63). 
A interpretação desta passagem deve ser considerada em seu marco temporal. O esporte adotava para a escola o modelo das instituições esportivas, nesse sentido, a caça de talentos e o desenvolvimento de capacidades físicas por meio de sua prática, eram objetivos da educação física escolar. O rendimento físico e motor passaram a ser o parâmetro avaliativo atrelado ao desempenho como elemento seletivo e de teor das atividades realizadas.

Não é por acaso, que como mostra Ghiraldelli (1991), pela resolução de número (18/2/1971), o governo introduziu para as turmas de $1^{\circ}$ e $2^{\circ}$ graus a possibilidade de criação de turmas de treinamento, ou seja, uma forma de concepção da própria EF no interior da escola, baseada na seleção e desenvolvimento de talentos esportivos para servir a nação. O esporte realmente exercia e talvez ainda exerça uma hegemonia nas aulas de educação física.

Nesse sentido, temos para a teorização e campo científico da área uma nova dimensão. É nesse momento como mostra Bracht (2014), a partir principalmente da década de 60, que o discurso sai do plano meramente pedagógico normativo, para algo de cunho fortemente cientificista, no sentido negativo de apologia à ciência; passou-se a questionar se a educação física era ou não uma ciência. Isso se deu principalmente póssegunda guerra mundial, muito no impulso da realidade de outros países (Alemanha, (anadá, etc.), nos quais o debate já tinha se constituindo bem antes.

Bracht (2014) afirma que esse período entre as décadas de 60 e 70, é crucial para o campo acadêmico e científico da educação física no Brasil, e o esporte passa a ser a grande figura dessa nova possibilidade de ascensão e status social para a ela. A própria denominação que surge nesse momento, de ciências do esporte, na tentativa de substituir o termo; Educação Física, demonstra os rumos perigosos e reducionistas que se pretendiam para a união entre educação física e ciência.

Foi nesse cenário, por exemplo, com a apresentação do diagnóstico da EF/Desportos no Brasil que se observaram as deficiências na produção teórica sobre a medicina esportiva no Brasil, sendo necessário o aumento de investimentos em pesquisas e incentivo para a pós-graduação e laboratórios qualificados. É nesse contexto que o próprio CBCE é fundado no final da década de 70. Daólio (1997) aprofunda esse debate mostrando o domínio dos médicos e fisiologistas sobre a entidade em suas primeiras gestões, ficando fáticos os rumos que ela poderia tomar com o cientificismo esportivista.

Queríamos mostrar com as breves passagens acima o momento de hegemonia desse tipo de atividade corporal (esporte), e como ele passa a ser socialmente consolidado como sinônimo de educação física. A expansão de mídias sociais ${ }^{4}$, grandes torneios mundiais, os chamados megaeventos esportivos, marcas esportivas globais, heróis nacionais e 4 Sobre a questão da internacionalização e expansão do esporte principalmente a partir da secunda metade do século XX, recomendamos a leitura de Tubino (1999; 2011), embora possamos ter fortes críticas às obras citadas, nelas o leitor pode encontrar de forma coesa e direta quais momentos históricos e fatores denotam as características do processo de crescimento do fenômeno esportivo em dimensão mundial. 
popularização de certos esportes, ajudam e ajudaram a materializar esse pensamento presente de certa forma até nossos dias, mesmo que com muitas críticas de várias correntes de pensamento de nossa área.

A reflexão que queríamos fazer, é que; do ponto de vista da formação humana multifacetada tratada por Marx e Engels (2009), da defesa da apropriação irrestrita do patrimônio histórico cultural da humanidade como direito de todos, ocorreram prejuízos históricos no desenvolvimento da educação física no Brasil. A história da de nossa área, se insere dentro de um circuito trágico de ordem moral, cívica e reprodutora de toda lógica de dominação e exploração de uma classe social sobre outra. Os diversos modelos de práticas corporais serviram de base para a consolidação que um projeto da classe burguesa da época que em primeiro momento foi revolucionária e hoje pode levar a humanidade à barbárie civilizatória a destruição de todas as classes.

Em síntese, a história da educação física até hoje conhecida tem sido a história da legitimação por meio das práticas corporais da exploração planejada da classe burguesa sobre o restante das organizações sociais que tratam com a cultura corporal. Escolas, clubes, instituições e centros de lazervêm contribuindo de modo controlado e racionalizado para a construção de consenso passivo entre as classes.

Isso não significa dizer que nunca tivemos resistência crítica mediante estes processos de dominação. Ghiraldelli (1991), ao identificar as tendências históricas da EF brasileira, comenta a respeito da educação física popular, como a corrente ligada com os setores subalternos da sociedade e também revolucionários; os quais buscavam modelos alternativos de práticas corporais e principalmente sua servidão as camadas populares de forma prazerosa e lúdica.

\section{Conclusão}

Quando falamos logo no título do último tópico, a constituição de um ideário e pensamento que "marca" a educação física. A palavra marca faz alusão justamente ao sentindo de um ferimento, sinal no corpo, ou melhor, dizendo um golpe, uma marca daquelas que faz parte de nossa história e que carregamos até nossos dias o peso de todos esses processos no cotidiano de nossas práticas e intervenções.

Muitos daqueles pensamentos, valores, dilemas e ações motoras promulgadas e vangloriadas há certo tempo ainda se fazem presente em escolas, cursos de formação superior e outros espaços de práticas corporais. Evidentemente não superamos por incorporação crítica a filosofia positivista e suas inserções em diversos campos da educação física brasileira. Realmente a ferida foi profunda, e paradoxalmente insultou os germes de sua possível superação, o que fez da década de 80 o momento de ebulição das críticas históricas, pedagógicas e estruturais da área.

Assim, concluímos que historicamente a educação física se relacionou com o 
positivismo, e tal fato ajudou no atraso histórico em campos como, a formação profissional e produção do conhecimento na área.

\section{Referências}

ANDERY, Maria Amália. et al. Para Compreender a ciência: uma perspectiva histórica. Rio de Janeiro: Garamond, 2014.

BERMAN, Marshall. Tudo o que é sólido desmancha no ar: A aventura da modernidade. São Paulo: Editora Schwarcz Ltda, 1986.

BRACHT, Valter. Educação Física \& ciência: cenas de um casamento (in) feliz. 4. ed. unijuí, 2014.

BRACHT, Valter. Educação Física e aprendizagem social. 2. ed. Porto Alegre: Magister, 1997. 122p.

BRACHT, Valter. Sociologia crítica do esporte: uma introdução. 3. ed. Coleção Educação física. Ijui: Editora Unijuí, 2005.

CASTELLANI, Lino. Educação física no Brasil: a história que não se conta. 19. ed. Campinas: Papirus, 2011.

COLETIVO DE AUTORES. Metodologia do ensino de educação física. São Paulo: Cortez, 2012.

DAOLIO, Jocimar. Educação Física brasileira: autores e atores da década de 80. São Paulo: Campina, 1997.

DUNNING, Eric; NOBERT, Elias. A busca da excitação. Lisboa, Difel, 1992.

GHIRALDELLI, Paulo. Educação Física progressista: A Pedagogia Crítico-Social dos Conteúdos e a Educação Física Brasileira. 3. ed. Edições Loyola, São Paulo: Brasil, 1991.

KONDER, Leandro. Marxismo e Alienação: contribuição para um estudo marxista do conceito de alienação. 2. ed. São Paulo, 2009(a).

KONDER, Leandro. O Marxismo na batalha das ideias. 2. ed. São Paulo: Expressão popular, 2009(b). 
LOVISOLO, Hugo. Pós-Graduação e Educação Física: Paradoxos, tensões e diálogos. Revista Brasileira de Ciência do Esporte, Florianópolis, v.20, n.1, set/98.

MARX, Karl. Manuscritos econômicos e filosóficos. São Paulo: Expressão popular, 2010. MARX, Karl; ENGELS, Friedrich. Manifesto do partido comunista. São Paulo: Boitempo, 2010.

SANTOS, Milton. Por uma outra globalização: do pensamento único a consciência universal. 6. ed. Rio de Janeiro: Recorde, 2001.

SEVERINO, Antônio. Metodologia do trabalho científico. São Paulo: Cortez Editora, 2002. SOARES, C. L. Educação Física: Raízes Européias e Brasil. Campinas, SP: Autores Associados, 2007.

SOARES, C. L. Imagens da Educação no corpo. Estudo da ginástica francesa no século XIX. Campinas, SP: Autores Associados, 2005.

STIGGER, Marco. Educação Física esporte e diversidade. Campinas, SP: Autores Associados, 2005.

TUBINO, Manuel. Dimensões sociais do esporte. 3. ed. São Paulo: Cortez, 2011.

TUBINO, Manuel. O que é Esporte. São Paulo: Brasiliense, 1999. 